Proceedings

\title{
Influence of the Use of Hydrocolloids in the Development of Gluten-Free Breads from Colocasia esculenta Flour ${ }^{\dagger}$
}

\author{
Jehannara Calle 1,2, Yaiza Benavent-Gil ${ }^{2}$ and Cristina M. Rosell 2,* \\ 1 Food Research Institute for the Food Industry (IIIA), Carretera al Guatao km 3 1⁄2, La Lisa, \\ La Habana 17100, Cuba; yannaracalle@gmail.com \\ 2 Institute of Agrochemistry and Food Technology (IATA-CSIC), C/ Agustin Escardino, 7, Paterna, \\ 46980 Valencia, Spain; yaizabenavent@gmail.com \\ * Correspondence: crosell@iata.csic.es; Tel.: +34-9639-000-22; Fax: +34-9636-363-01 \\ + Presented at the 2nd International Conference of Ia ValSe-Food Network, Lisbon, Portugal, \\ 21-22 October 2019.
}

Published: 5 August 2020

\begin{abstract}
Colocasia esculenta represents an alternative non-gluten ingredient due to its healthy properties. The objective of this study was to explore the breadmaking potential of Colocasia spp. cormel flour combined with hydrocolloids (hydroxypropyl methylcellulose, xanthan gum, guar gum). A total of three formulations were tested. Breads were characterized by assessing their technological qualities: moisture, specific volume, volume, hardness and weight loss. The quality parameters were similar to other gluten-free breads. Overall, Colocasia spp. flour can be used to produce gluten-free breads with similar technological quality parameters than those previously reported with common gluten-free flours.
\end{abstract}

Keywords: bread; Colocasia esculenta; gluten-free; hydrocolloids

\section{Introduction}

In the field of the development of gluten-free bread, the replacement of the gluten network has been largely researched to meet the requirements of people with coeliac disease in order to improve the sensory, technological and nutritional quality of gluten-free breads [1]. Traditionally, most gluten-free products were made with rice, maize, sorghum, soy, buckwheat flours and starches from maize, potato, cassava, rice or beans [2]. Some researchers have used gums, hydrocolloids, enzymes and other ingredients to improve their minimal structure-building potential [3]. Thus far, hydrocolloids have been blended with GF (gluten-free) flours to improve the technological quality of end-products [4]. The Colocasia esculenta (L.) Schott (Colocasia spp.) rhizome is grown largely in Cuba [5]. Despite evidence of the positive benefits of this flour, there are few studies about its utilization in GF breadmaking [5]. The objective of this investigation was to explore the breadmaking potential of Colocasia spp. cormel flour combined with hydrocolloids (Hydroxypropylmethylcellulose: HPMC, xanthan gum, guar gum).

\section{Materials and Methods}

\subsection{Materials}

Cormels from freshly Colocasia spp. MC-2012, harvested at 9-13 months of maturity, were collected from the National Institute of Tropical Food Research Farms in Cuba, and the rhizomes 
were milled [5]. Hydroxypropylmethylcellulose (HPMC, Methocel $\left.{ }^{\mathrm{TM}} \mathrm{K} 4 \mathrm{M}\right)$ was donated by Dow Pharma \& Food Solutions (La Plaine Saint Denis, France). Guar gum-3500 and food-grade xanthan gum were acquired from EPSA (Valencia, Spain) and Jungbunzlauer (Wulzeshofen, Austria), respectively. All other ingredients were acquired in the local market and all reagents were of analytical grade.

\subsection{Flour Characteristics and Baking Process}

The methods used to determine the flour characteristics - moisture, total nitrogen, fat, ash and crude fiber content-were AACC, 1999 [6]; 78 AOAC, 1990; AACCI 79 Method 44-15.02; AACCI methods 46-12.01; AACC Method 30- 25.0; AACC Method 08-01.01 and AOAC Method 973.18, respectively. Carbohydrate content was estimated by difference. Water binding capacity (WBC) was analyzed according to the method described by [2]. Bread recipe was based on those previously selected $[7,8]$ (Table 1) but replacing the flour with Colocasia spp. flour. Mixing was carried out in a Robot Coupe RM8 (Barcelona, Spain) at speed 3 for $8 \mathrm{~min}$, and the rest of the breadmaking conditions were as previously reported, following the method described by [3].

Table 1. Gluten-free bread recipes.

\begin{tabular}{lccc}
\hline Ingredients & F1 & F2 & F3 \\
\hline Flour $(\mathrm{g})$ & 100 & 100 & 100 \\
Water $(\mathrm{g})$ & 227 & 227 & 227 \\
Salt $(\mathrm{g})$ & 1.5 & 1.5 & 1.5 \\
Compressed Yeast $(\mathrm{g})$ & 3 & 3 & 3 \\
Sugar (g) & 2 & 2 & 2 \\
Oil (g) & 2 & 2 & 2 \\
HPMC (g) & - & 2 & 0.29 \\
Xanthan gum (g) & - & - & 0.21 \\
Guar gum (g) & - & - & 0.50 \\
\hline
\end{tabular}

$100 \%$ of rhizome flour (F1); $100 \%$ of flour blended with hydrocolloids (F2 and F3).

\subsection{Quality Assessment of the GF Breads}

Quality parameters were evaluated as previously described by [9]. Bread moisture content and volume were evaluated following [6] and the rapeseed displacement method, respectively. Specific volume and weight loss during baking $\left(\mathrm{cm}^{3} / \mathrm{g}\right)$ were calculated as the ratio between the volume of the bread and its weight and weighing the pans before and after baking, respectively. These measurements were replicated three times. The hardness was evaluated using a Texture Analyzer TA-XT2i (Stable Micro Systems, Surrey, UK).

\subsection{Statistical Analysis}

The data were reported as means \pm standard deviation of two replicates. The effect of different additives was analyzed by ANOVA, using Statgraphics Centurion XVII software (Bitstream, Cambridge, MA, USA).

\section{Results}

\subsection{Proximate Composition of Raw Flour}

The proximate composition of the Colocasia spp. flour was as follows: moisture: $6.33 \% \pm 0.02 \%$, protein: $8.28 \% \pm 0.07 \%$, ash: $5.04 \% \pm 0.00 \%$, fat: $0.53 \% \pm 0.00 \%$, crude fiber: $4.4 \% \pm 0.2 \%$ and carbohydrate: $75.4 \% \pm 0.3 \%$. Despite Colocasia spp. cormels exhibiting a high carbohydrate content, it contained an important amount of minerals and fiber. The protein content was lower than that reported for teff and buckwheat flours but higher than maize, rice, cassava or sweet potato flours [10-12]. 


\subsection{Effect of Additives in Colocasia spp. Cormel Flour-Based Breads}

The moisture content and weight loss were significantly different $(p<0.05)$ and as the moisture content decreased, the weight loss increased (Figure 1). In general, the addition of hydrocolloids resulted in higher moisture content than that observed in F1 breads. They also showed lower weight loss during baking, likely due to the water retention ability of hydrocolloids to retain water molecules. As expected, breads were visually dark, which could be attributed to the natural color of raw Colocasia spp. flour, which displayed $81.05 \pm 0.36,1.17 \pm 0.07$ and $14.63 \pm 0.45$ for $L^{*}, a^{*}$ and $b^{*}$, respectively.

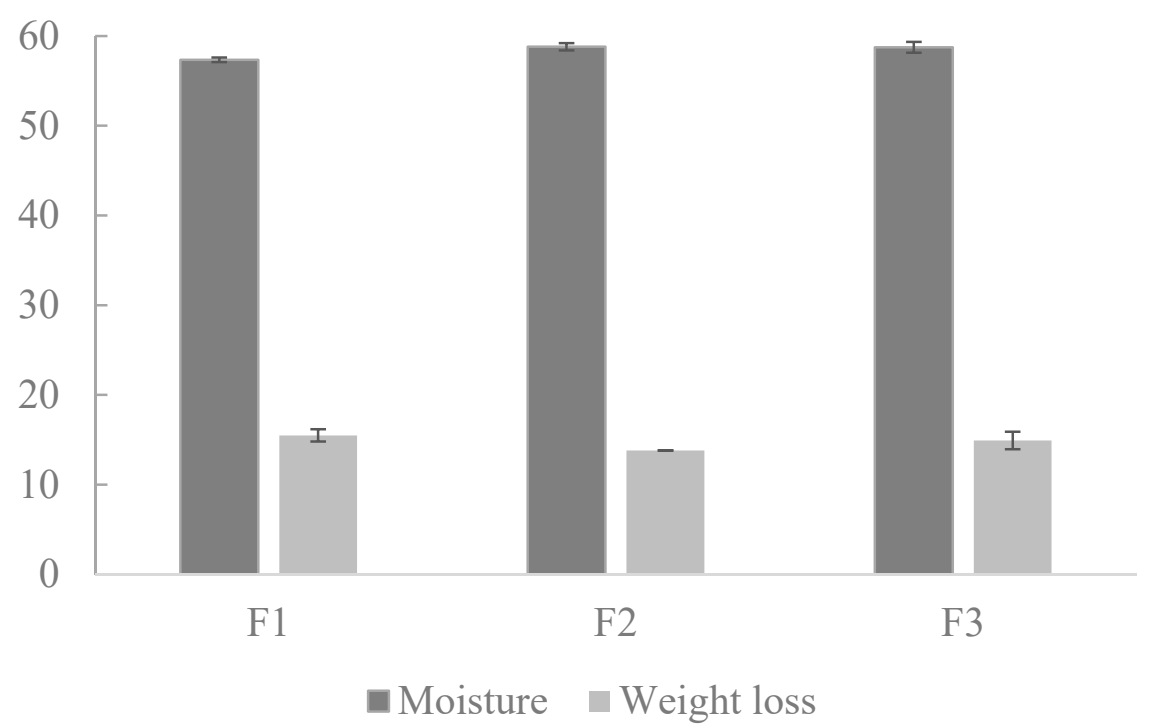

Figure 1. Weight loss and moisture content: 100\% of rhizome flour (F1); $100 \%$ of flour blended with hydrocolloids (F2 and F3).

Hardness values ranged from $263 \pm 38$ to $361 \pm 17$ g. Overall, F1 breads displayed the highest values. In gluten-free breads, hydrocolloids usually led to lower crumb hardness [13]. Nonetheless, Sasaki [14] explained that their effect seems to be also dependent on the flour used; thus, it seems that, with cormel flour, the strengthening action of the hydrocolloids was not enough to hold the carbon dioxide during proofing and baking. In general, the bread without inclusion of hydrocolloids showed less hardness and a higher specific volume $(1.74 \pm 0.03 \mathrm{~mL} / \mathrm{g})$.

\section{Conclusions}

In order to develop a bread with a softer breadcrumb structure from Colocasia spp., flour is not required to include HPMC in the form of either a blend of HPMC, guar gum and xanthan gum at levels included. In this study, it can be concluded that hydrocolloids had a significant effect on the moisture content and weight loss of breads, but their effect was dependent on the type of hydrocolloids. Overall, Colocasia spp. flour can be used to produce GF breads with similar technological quality parameters to those previously reported with common GF flours.

Funding: Spanish Ministry of Science, Innovation and Universities (RTI2018-095919-B-C21), the European Regional Development Fund and Generalitat Valenciana (Project Prometeo 2017/189).

Acknowledgments: The authors want to thank Ia ValSe-Food-CYTED (119RT0567) for financing the participation in the meeting. 


\section{References}

1. Capriles, V.D.; Arêas, J.A.G. Novel approaches in gluten-free breadmaking: Interface between food science, nutrition, and health. Compr. Rev. Food Sci. Food Saf. 2014, 13, 871-890, doi:10.1111/1541-4337.12091.

2. Cornejo, F.; Rosell, C.M. Influence of germination time of brown rice in relation to flour and gluten free bread quality. J. Food Sci. Technol. 2015, 52, 6591-6598, doi:10.1007/s13197-015-1720-8.

3. Calle, J.; Benavent-Gil, Y.; Rosell, C.M. Development of gluten free breads from Colocasia esculenta flour blended with hydrocolloids and enzymes. Food Hydrocol. 2020, 98, 105243, doi:10.1016/j.foodhyd.2019.105243.

4. Masure, H.G.; Fierens, E.; Delcour, J.A. Current and forward looking experimental approaches in glutenfree bread making research. .J. Cereal Sci. 2016, 67, 92-111, doi:10.1016/j.jcs.2015.09.009.

5. Calle, J.; Benavent-Gil, Y.; Garzón, R.; Rosell, C.M. Exploring the functionality of starches from corms and cormels of Xanthosoma sagittifolium. Int. J. Food Sci. Technol. 2019, 54, 2494-2501, doi:10.1111/ijfs.14207.

6. AACC. Method 56-30.01 Water Hydration Capacity of Protein Materials, 11th ed.; Method 44-15.02 MoistureAir-Oven Methods, Approved Methods of Analysis; AACC International: St. Paul, MN, USA, 1999.

7. Calle, J.; Villavicencio MNd Rosell, C.M.; Bernabé-Marques, C.J. Influencia de mezclas de hidrocoloides en la reología de la masa del pan libre de gluten. Cienc. Tecnol. Aliment. 2014, 2, 37-42.

8. Marco, C.; Rosell, C.M. Breadmaking performance of protein enriched, gluten-free breads. Eur. Food Res. Technol. 2008, 227, 1205-1213, doi:10.1007/s00217-008-0838-6.

9. Matos, M.E.; Rosell, C.M. Quality Indicators of Rice-Based Gluten-Free Bread-Like Products: Relationships Between Dough Rheology and Quality Characteristics. Food Bioprocess Technol. 2013, 6, 2331-2341, doi:10.1007/s11947-012-0903-9.

10. Hager, A.-S.; Arendt, E.K. Influence of hydroxypropylmethylcellulose (HPMC), xanthan gum and their combination on loaf specific volume, crumb hardness and crumb grain characteristics of gluten-free breads based on rice, maize, teff and buckwheat. Food Hydrocol. 2013, 32, 195-203, doi:10.1016/j.foodhyd.2012.12.021

11. Pasqualone, A.; Caponio, F.; Summo, C.; Paradiso, V. M.; Bottega, G.; Pagani, M. A. Gluten-free bread making trials from cassava (manihot Esculenta Crantz) flour and sensory evaluation of the final product. Int. J. Food Prop. 2010, 13, 562-573, doi:10.1080/10942910802713172.

12. Yadav, A. R.; Guha, M.; Tharanathan, R.; Ramteke, R. Changes in characteristics of sweet potato flour prepared by different drying techniques. LWT Food Sci. Technol., 2006, 39, 20-26, doi:10.1016/j.lwt.2004.12.010.

13. Liu, X.; Mu, T.; Sun, H.; Zhang, M.; Chen, J; Fauconnier, M. L. Influence of different hydrocolloids on dough thermo-mechanical properties and in vitro starch digestibility of gluten-free steamed bread based on potato flour. Food Chem. 2018, 239, 1064-1074, doi:10.1016/j.foodchem.2017.07.047

14. Sasaki, T. Effects of xanthan and guar gums on starch digestibility and texture of rice flour blend bread. Cereal Chem. 2018, 95, 177-184, doi:10.1002/cche.10024.

(C) 2020 by the authors. Licensee MDPI, Basel, Switzerland. This article is an open access article distributed under the terms and conditions of the Creative Commons Attribution (CC BY) license (http://creativecommons.org/licenses/by/4.0/). 